\title{
On Launching a New Twenty-first Century Quarterly Journal, Nuclear Medicine and Molecular Imaging
}

\author{
Yong-Whee Bahk
}

Published online: 24 February 2010

(C) Korean Society of Nuclear Medicine 2010

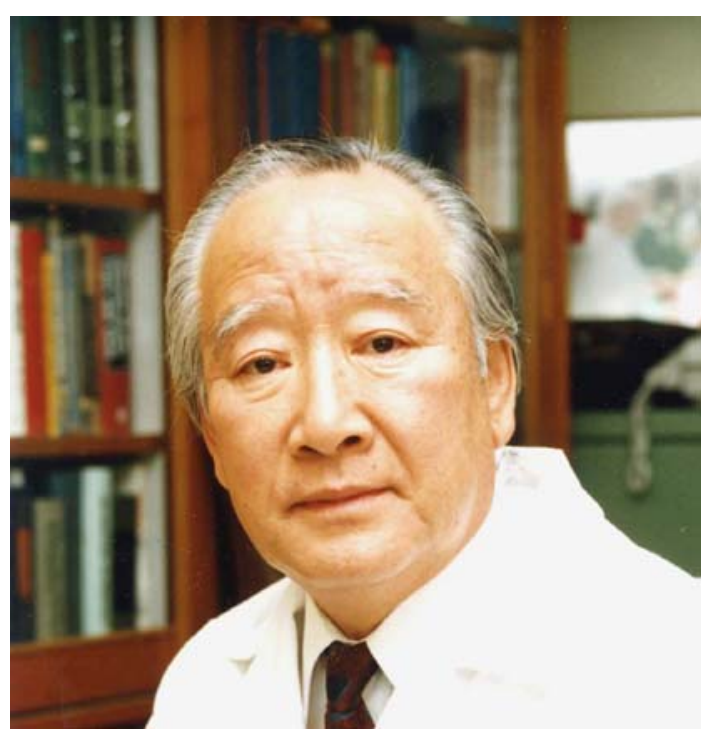

Yong-Whee Bahk, Honorary Editor

Any nuclear-medicine physician or scientist who historically traces the origin of nuclear medicine will encounter the name of Democritus to impress us with an inspiring vision. A disciple of Leucippus, Democritus was an esteemed philosopher-scientist, who introduced and developed the earliest concept of the atom in the late fifth/early fourth century BC. Curiously enough, the philosopher suffered from mental illness, which was cured by Hippocrates [1].

Y.-W. Bahk $(\bowtie)$

PET/CT Center and Department of Nuclear Medicine,

Seoul Sung-Ae Hospital, 451,

Shingil-1-dong, Youngdeungpo-gu,

Seoul 150-960, Korea

e-mail: ywbahk@hanmail.net
Thus, today's nuclear medicine, with its influential prosperity, was remotely conceived by an atomist and a physician, and some 22 centuries elapsed before Robert Boyle, Antoine L. Lavoisier, and John Dalton refined the atomic concept afresh after the Renaissance [2]. The atom was so gestated to be born as the 'radioactive celebrity' of modern medicine in the mid-twentieth century when the cyclotron and atomic reactor were constructed to richly produce radioisotopes, along with the advent of gamma cameras, followed by SPECT and PET. Now these techniques are ardently being fused with anatomical imaging methods such as CT, MRI, and ultrasound, further exploring new horizons. Witnessing these great strides, the remarks pointed out by Sylvanus P. Thompson in 1897 [2] in praising the discovery of X-rays by Wilhelm C. Roentgen and radium by Marie and Pierre Curie hold true for nuclear medicine, too: "The discoverer is but the descendant of his scientific forefathers." This is the way that nuclear medicine will grow eternally and it is hoped that Nuclear Medicine and Molecular Imaging (NMMI) will be a good messenger, faithful spreader and worthwhile archivist.

Nuclear medicine has served, is serving, and will serve the needs of the sick by providing the unique qualitative and quantitative information on function, metabolism and molecular-genetic behavior that is characteristic of, and often specific to, organs and cells in normal and morbid conditions $[3,4]$. The specificity and common value of nuclear medicine in diagnosing the diseases of the brain, heart, endocrine glands, musculoskeletal system, and other organs and organ systems are just one aspect of what have been achieved during the short period - still little more than half a century-after the Second World War. In addition, the use of potent radionuclides in the form of simple elements, salts, and pharmaceuticals have provided and will 
provide otherwise unobtainable tools to heal patients with a great variety of diseases from the benign to the most agonizing [5].

Truly, the horizons and domains of nuclear medicine have become immensely broadened and deepened far beyond our expectations and imaginations, now ever more increasingly tantalizing the seekers for communication arenas. The arenas are for new discoveries, novel ideas, and rare opinions such as multi-parametric molecular imaging [6] and, at the same time, for ensuring that more traditional science is not neglected. There is still a constant need to reflect upon the classic aspects of knowledge which inform deeper understanding of the new and which might fall into oblivion without refinement through further exacting experiments.

It is dearly hoped that this new quarterly journal, NMMI, the successor to the 47-year-old Korean Journal of Nuclear Medicine, will effectively serve as one such avenue of communication, providing an equitable forum for both cutting-edge and classical nuclear medicine. The journal will have a wide embrace, welcoming all respectable brains and warm hearts for patients and science. As Aristotle stated a long time ago, "One might begin with philosophy but would end with medicine; or start with medicine and find oneself in philosophy." Similarly, we started with nuclear medicine, but might eventually find ourselves in the realm of philosophy.

Acknowledgement Finally, we would like to take up this rare occasion to gratefully acknowledge admirable idea and cooperation of Dr. Ute Heilmann of Springer-Verlag, Heidelberg in achieving this conjoint publication of Nuclear Medicine and Molecular Imaging.

\section{References}

1. Lyons AS, Petrucelli RJ II (1987) Hippocrates. In: Lyons AS, Petrucelli RJ II (eds) Medicine: an illustrated history. Harry N. Abrams, New York, pp 206-217

2. Glasser O, Quimby EH, Taylor LS, Weatherwax JL (1954) Milestones in radiology. In: Glasser O, Quimby EH, Taylor LS, Weatherwax JL (eds) Physical foundations of radiology, 2nd edn. Paul B Hoeber, New York, pp 1-16

3. Gambhir SS (2008) Introduction. J Nucl Med 49(Suppl 6):1-4

4. Kang JH, Chung JK (2008) Molecular-genetic imaging based on reporter gene expression. J Nucl Med 49(Suppl 6):164-179

5. Choi SJ, Hong YD, Lee SY (2006) Therapeutic radiopharmaceuticals. Nucl Med Mol Imaging 44:58-65

6. Zaidi H (2009) Navigating beyond the 6th dimension: a challenge in the era of muliti-parametric molecular imaging. Eur J Nucl Med Mol Imaging 36:1025-1028 